\title{
Gerald Nestler
}

Artist and independent researcher, Austria

\section{Suhail Malik}

Goldsmiths, University of London, UK

The editorial premise of this special issue is that the adage 'art and money do not mix' is now wholly untenable. As detailed in our extended interview with Clare McAndrew, the art market has grown rapidly over the last twenty years, leading to systemic and structural changes in the art field. For some, this growth of the market and its significance for art is an institutional misfortune that, for all of its effects, is nonetheless inconsequential to the normative claim that art and money shouldn't mix. This commonplace premise looks to keep the sanctity or romance of art from the business machinations of market mechanisms, as eloquently summarised by Oscar Wilde's definition of cynicism ('knowing the price of everything and the value of nothing'). This issue repudiates that normative moral code, and precisely for the reasons just stated: by now, the interests of the art market permeate all the way through the art system. The interests of the art market shape what is exhibited and where; what kinds of discourse circulate around which art (or even as art) and in what languages; and what, in general, is understood to count as art. In short, the art market - comprising mainly of collectors, galleries and auction houses - is now the primary driver in what is valuable in art.

And it is not just value and valuation that are transformed by the recent expansion of the art market. Together with increased interest in art by both financial firms and individuals from that sector as private collectors-investors, the expansion of financial markets in a period also characterised by rapid growth in the art market and increased power within the art field for its highly commercialised operators may, combined, suggest a common endorsement of speculation and risk across these sectors. Contemporary art's speculations and unmooring of stable meanings or coordinates are met by risk-based, speculative accumulation strategies on the side of finance itself.

Convenient as such a formal explanation may be, it however relies on two abstract nouns (speculation and risk) which have different meanings in each of these sectors. For its part, 'speculation' in contemporary art identifies its manifestation of innovative semantic and cultural possibilities, realised because it has no definition and is conceptually adaptable. 'Risk' is here the displacement of semantic security and its ramifications. At best, that displacement of conventions makes for a future that is less pre-programmed. In finance, on the other hand, both 'speculation' and 'risk' are mobilised as conditions of capital

\section{Corresponding author:}

Gerald Nestler, Neulinggasse 9, 1030 Vienna, Austria.

Email: mail@geraldnestler.net 
accumulation drawing on an unknown future to determine interventions into markets. 'Black Swan' exceptions notwithstanding, the meaning of risk is stabilised in finance via standardised metrics (not least through the market itself as an operational constraint). For example, while art has been integrated into finance as an alternative investment to hedge and diversify portfolios against risks in traditional asset classes, contemporary art serves to leverage the value of art-based portfolios (collections) and as a result brings liquidity and arbitrage opportunities into the total market.

Finance and contemporary art cannot therefore be identified on the basis of these terms common to both. But, for the practical and historical reasons mentioned in the opening lines above, neither can they be disentangled. And the distinction between kinds of speculative risk serves as a useful schema to formulate the key themes taken up by the contributors to this special issue. On one side of this distinction, the transformation of the art market into an increasingly finance-facing configuration, as well as its consequences for contemporary art's historical-conventional claims to semantic and affective change, are elaborated in the interview with McAndrew, the articles by Victoria Ivanova and Laura Lotti, and the art projects of Offshore and ISCA. On the other side, the articles by Emily Rosamond and Christopher Wood et al., together with the art interventions by Paulo Cirio, Sylvia Eckermann and Gerald Nestler, and UBERMORGEN, mobilise art's speculative challenge to examine the consequences of such a transformation, and also to modify standard financial practices.

A particular focus of the latter set of contributions is the blockchain technology underlying Bitcoin: an automated distributed ledger that can be deployed to transform the current critical role of the dealer in the art system. Blockchain technology and other advances in 'fintech' are promoted within the financial sector as disrupters of its conventional institutional structures (extended by Rosamond to include social impact bonds). Our interest in such 'disruption' is not only that the mechanisms of accumulation are shaken up, but also their meaning. Yet, as several of the contributors to this special issue contend, what is no less significant here is that the relay between finance and art also partially reworks each of these sectors, both by changing the dynamics of the art field as a whole and by reconfiguring the transactions of particular exchanges, not to mention challenging the very distinction between finance and art as sectors.

By way of conclusion, we can add that our editorial stance is to bring to the forefront the interaction and manipulation of art and finance on both sides as a positive condition for the changes wrought by finance as a sectorial, technical and operational system. We have purposely not solicited contributions that provide allegories, figurations, metaphors or other mythifying caricatures of finance, though these approaches are arguably more common in contemporary art and certainly more prominent in the conventional critical stance on 'finance societies'. For us, such critical renditions serve to further mystify finance as a sector and a technical apparatus in the broader cultural space, as well as maintaining art's putative exteriority to it. We take as the primary political and epistemological aim of this special issue to contribute to the demystification of not only financial operations as practical possibilities that can be multifunctional, but also of how finance and its operational logics of accumulation extend well beyond its narrowly defined markets into the very practices that claim to be utterly distinct from them. 